\title{
Clinical and laboratory characteristics of chronic spontaneous urticaria with connective tissue diseases: A cross-sectional study
}

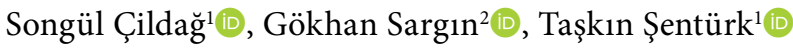 \\ ${ }^{1}$ Department of Internal Medicine, Division of Immunology and Allergy Diseases, Adnan Menderes University, Faculty of Medicine, Aydin, Türkiye \\ ${ }^{2}$ Department of Internal Medicine, Division of Rheumatology, Adnan Menderes University, Faculty of Medicine, Aydin, Türkiye
}

\begin{abstract}
Objectives: The aim of this study was to investigate the frequency of connective tissue diseases (CTDs) in patients with chronic spontaneous urticaria (CSU) and to evaluate clinical and laboratory characteristics of CSU accompanied by CTDs.

Patients and methods: Between January 2017 and December 2020, a total of 390 CSU patients (120 males, 270 females; mean age: $38.9 \pm 13.7$ years; range, 18 to 78 years) were included in the study. Clinical and laboratory characteristics of CSU in patients with and without CTD were analyzed. Results: A total of $6.4 \%$ patients $(n=25)$ with CSU had CTD, and the rate was found to be $8.9 \%$ in female patients $(n=24)$. In these patients, Sjögren syndrome (SS) was seen in $15(5.5 \%)$, rheumatoid arthritis in five (1.85\%), undifferentiated connective tissue disease in three (1.11\%), and systemic lupus erythematosus in one ( $0.37 \%)$. Anti-thyroglobulin antibody, rheumatoid factor, anti-cyclic citrullinated peptide antibody, antinuclear antibody positivity, low complement 4 level, and erythrocyte sedimentation rate were significantly different between CSU patients with and without CTD ( $p=0.013, p<0.001, p<0.001, p<0.001, p=0.0182, p<0.001$, respectively).
\end{abstract}

Conclusion: Our study results suggest that CSU is associated with CTDs, particularly with Sjögren syndrome. Every patient diagnosed with CSU should be questioned about rheumatic symptoms, particularly female patients and those having later-onset CSU.

Keywords: Autoimmunity, chronic spontaneous urticaria, connective tissue diseases, Sjögren syndrome.

Urticaria is characterized by the development of wheals or angioedema or both. Chronic urticaria $(\mathrm{CU})$ is defined as urticaria lasting longer than six weeks, and it is classified as chronic spontaneous urticaria (CSU) and chronic inducible urticaria (CIU-specific eliciting factor involved). ${ }^{1}$ Although the pathogenesis is unclear, autoimmunity is thought to be involved in the etiology. Autoimmunity is defined in two forms: type 1 and type 2b. ${ }^{2}$ Immunoglobulin (Ig) $\mathrm{E}$ autoantibodies against thyroid peroxidase, ${ }^{3}$ double-stranded deoxyribonucleic acid
(dsDNA), ${ }^{4}$ interleukin (IL)-24, tissue factor, and thyroglobulin ${ }^{5,6}$ have been shown to implicate in IgE-mediated type 1 autoimmunity (autoallergy), whereas IgG or IgM autoantibodies have been shown to develop against IgE or, its high-affinity receptor (FcER1), in type $2 \mathrm{~b}$ autoimmunity. ${ }^{7}$

Thyroid diseases are the most common autoimmune diseases accompanying CU. ${ }^{8}$ In addition, type 1 diabetes mellitus, celiac disease, and some of the connective tissue diseases (CTDs) are more frequent in women with $\mathrm{CU}{ }^{8}$ Anti-nuclear antibodies (ANA) and anti-thyroid

Received: February 06, 2021 Accepted: June 27, 2021 Published online: December 24, 2021

Correspondence: Songül Çildağ, MD. Adnan Menderes Üniversitesi, İç Hastalıkları Anabilim Dalı, İmmünoloji ve Alerji Hastalıkları Bilim Dalı, 09010 Efeler, Aydın, Türkiye. Tel: +90 256 - 4441256 e-mail: songulcildag@yahoo.com

\section{Citation:}

Çildağ S, Sargın G, Şentürk T. Clinical and laboratory characteristics of chronic spontaneous urticaria with connective tissue diseases: A cross-sectional study. Arch Rheumatol 2022;37(2):205-211. 
antibodies are the most common autoantibodies in patients with CU. ${ }^{8-12}$

The prevalence of $\mathrm{CU}$ in the general population is between 0.5 and $5 \%$, and it is more common in women in their third to fifth decades of life. ${ }^{9}$ Also, CTDs are more common in women of similar ages as in CU. In the present study, we aimed to investigate the frequency of CTD in patients with CSU and to evaluate laboratory and clinical characteristics of CSU accompanied by CTDs.

\section{PATIENTS AND METHODS}

This cross-sectional study was conducted at Adnan Menderes University, Faculty of Medicine, immunology and allergy clinic between January 2017 and December 2020. A total of 390 CSU patients (120 males, 270 females; mean age: $38.9 \pm 13.7$ years; range, 18 to 78 years) were included in the study. Chronic spontaneous urticaria was defined as spontaneous appearance of wheals, angioedema or both for more than six weeks due to known or unknown causes. ${ }^{1}$ Patients were excluded if they had inducible urticaria, urticarial vasculitis, acute urticaria, angioedema without urticaria, or mastocytosis. Demographic and laboratory data of the patients were evaluated from archive documents. Demographic data included age, sex, disease duration, angioedema, presence of rheumatic diseases (history or newly diagnosed rheumatic diseases). Rheumatic diseases included autoinflammatory diseases (e.g., familial Mediterranean fever), vasculitis, spondyloarthropathy (e.g., ankylosing spondylitis [AS]), crystal arthropathy, CTDs (e.g., rheumatoid arthritis [RA], systemic lupus erythematosus [SLE], Sjögren syndrome [SS]). Laboratory data included serum total IgE, specific immunoglobulin $\mathrm{E}$ (sIgE) according to skin prick test and/or serum specific IgE, parasite in the stool, Hepatitis $\mathrm{B}$ surface antigen ( $\mathrm{HBsAg})$, anti-hepatitis $\mathrm{C}$ virus (HCV), anti-human immunodeficiency virus (HIV), ANA, IgG anti-thyroglobulin antibody (anti-Tg), IgG anti-thyroperoxidase antibody (anti-TPO), rheumatoid factor (RF), anti-cyclic citrullinated peptide (anti-CCP), complement 3 (C3), complement 4 (C4), serum IgG, serum IgM, serum IgA, erythrocyte sedimentation rate (ESR), and C-reactive protein (CRP). Anti-nuclear antibody positivity was accepted as a titer of
$1 / 100$. The patients were divided into two groups according to the presence of CTDs, and their demographic and laboratory data were compared.

\section{Statistical analysis}

Statistical analysis was performed using the IBM SPSS version 21.0 software (IBM Corp., Armonk, NY, USA). Data were presented in mean \pm standard deviation (SD), median (min-max) or number and frequency. The Kolmogorov-Smirnov test was used to determine the normal distribution of the data. Comparisons between the groups were analyzed by either independent samples $\mathrm{t}$-test or Mann-Whitney $\mathrm{U}$ test according to the distribution of normality. The chi-square test was used for assessment of differences between qualitative variables. A $p$ value of $<0.05$ was considered statistically significant.

\section{RESULTS}

The median total IgE level was 86 (range, 8 to 4,759 ) IU/mL, and $54.9 \%$ of the patients had a total IgE below 100 (reference range: 0 to 100 ) $\mathrm{IU} / \mathrm{mL}$. Specific IgE positivity was present in $27.6 \%$ of the patients, and angioedema accompanying urticaria was present in $41.5 \%$. Anti-Tg $(p=0.004)$ and ANA $(p<0.001)$ were more frequently positive, and serum IgM levels $(p<0.001)$ and ESR $(p<0.001)$ were found to be higher in female patients compared to male patients (Table 1).

There were 10 patients with a history of rheumatic disease (RA [n=3], AS [n=4], and gout $[\mathrm{n}=3]$ ), and 22 patients with CSU were newly diagnosed with the rheumatic disease at the time of admission (SS [n=16], RA [n=2], SLE [n=1], undifferentiated CTD [UCTD] [n=3]). About $6.4 \%$ of all patients with CSU had CTD, and the rate was found to be $8.9 \%$ in female patients (Table 1).

The median age was 51.5 (range, 19 to 76) years which was significantly higher $(p<0.001)$ in the patients with CTD compared to the patients without CTD. A significant difference was also found in terms of sex $(p<0.001)$. Anti-Tg, RF, anti-CCP, ANA positivity, low C4 level, and ESR were found to be significantly different between CSU patients with and without CTD $(p=0.013$, $\mathrm{p}<0.001, \mathrm{p}<0.001, \mathrm{p}<0.001, \mathrm{p}=0.0182, \mathrm{p}<0.001$, respectively). Total IgE levels were lower and 


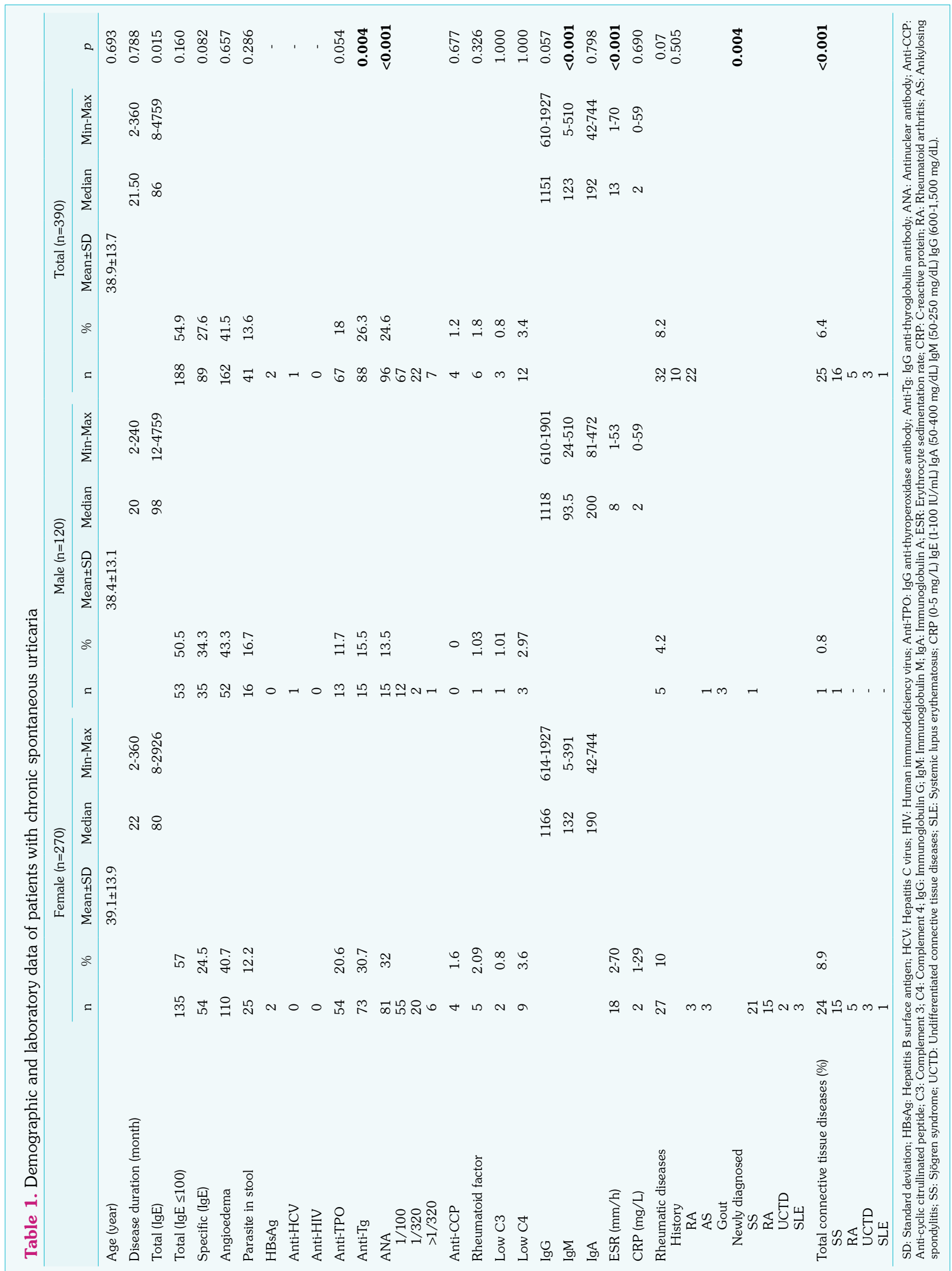


Table 2. Demographic and laboratory data of patients with CSU according to the presence of connective tissue disease

\begin{tabular}{|c|c|c|c|c|c|c|c|c|c|}
\hline & \multicolumn{4}{|c|}{ CSU with CTD (n=25) } & \multicolumn{4}{|c|}{ CSU without CTD (n=365) } & \multirow[b]{2}{*}{$p$} \\
\hline & $\mathrm{n}$ & $\%$ & Median & Min-Max & $\mathrm{n}$ & $\%$ & Median & Min-Max & \\
\hline Age (year) & & & 51.5 & $19-76$ & & & 37 & $18-78$ & $<0.001$ \\
\hline $\begin{array}{l}\text { Sex } \\
\quad \text { Female }\end{array}$ & 24 & 96 & & & 246 & 67.3 & & & $<0.001$ \\
\hline CSU duration (month) & & & 12 & $2-240$ & & & 23 & $2-360$ & 0.167 \\
\hline Total (IgE) & & & 65 & $11-2157$ & & & 86.50 & 8-4759 & 0.338 \\
\hline Total $(\mathrm{IgE} \leq 100)$ & 12 & 75 & & & 176 & 54 & & & 0.08 \\
\hline Specific (IgE) & 8 & 38.1 & & & 81 & 26.9 & & & 0.313 \\
\hline Angioedema & 10 & 40 & & & 152 & 41.6 & & & 1.000 \\
\hline Parasite in stool & 3 & 13 & & & 38 & 13.7 & & & 1.000 \\
\hline Anti-TPO & 7 & 28 & & & 60 & 17.2 & & & 0.181 \\
\hline Anti-Tg & 10 & 52.6 & & & 78 & 24.7 & & & 0.013 \\
\hline $\begin{array}{l}\text { ANA } \\
1 / 100 \\
1 / 320 \\
>1 / 320\end{array}$ & $\begin{array}{c}18 \\
12 \\
3 \\
3\end{array}$ & 72 & & & $\begin{array}{c}78 \\
55 \\
19 \\
4\end{array}$ & 23.0 & & & $<0.001$ \\
\hline Anti-CCP & 3 & 12 & & & 1 & 0.3 & & & $<0.001$ \\
\hline Rheumatoid factor & 5 & 20.8 & & & 1 & 0.03 & & & $<0.001$ \\
\hline Low C3 & 0 & 0 & & & 3 & 0.9 & & & 1.000 \\
\hline Low C4 & 2 & 8.7 & & & 10 & 3 & & & 0.0182 \\
\hline $\operatorname{IgG}$ & & & 1155 & $946-1521$ & & & 1159 & $946-1521$ & 0.750 \\
\hline IgM & & & 110 & $56-206$ & & & 123.5 & 5-510 & 0.498 \\
\hline $\operatorname{Ig} \mathrm{A}$ & & & 240.5 & $93-347$ & & & 191 & $42-744$ & 0.469 \\
\hline Erythrocyte sedimentation rate & & & 30 & $6-70$ & & & 13 & $1-65$ & $<0.001$ \\
\hline C-reactive protein & & & 4 & $2-8$ & & & 2 & $0-59$ & 0.121 \\
\hline
\end{tabular}

Table 3. Antinuclear antibody subgroup distribution according to the presence of connective tissue disease

\begin{tabular}{|c|c|c|c|}
\hline & Total & CSU with CTD (n=25) & CSU without CTD $(n=365)$ \\
\hline & $\mathrm{n}$ & $\mathrm{n}$ & $\mathrm{n}$ \\
\hline Anti-SSA (Ro-60) & 9 & 7 & 2 \\
\hline Anti-SSA (Ro-52) & 7 & 6 & 1 \\
\hline Anti-SSB & 1 & 1 & - \\
\hline Anti-dsDNA & 6 & 2 & 4 \\
\hline Anti-centromere B & 3 & 1 & 2 \\
\hline Anti-Sm & 2 & 2 & - \\
\hline Anti-RNP/Sm & 1 & - & 1 \\
\hline Anti- PM-Scl 100 & 1 & - & 1 \\
\hline Anti-ribosomal $\mathrm{P}$ protein & 2 & 1 & 1 \\
\hline Anti-histon & 2 & 2 & - \\
\hline Anti-Jo-1 & 1 & 1 & - \\
\hline Anti-DFS-70 & 18 & 2 & 16 \\
\hline
\end{tabular}


specific IgE positivity was higher in CSU patients with CTD than those without CTD (Table 2).

According to the ANA subgroup analysis, anti-SSA antibodies were found to be most common in patients with $\mathrm{CTD}$, and dense fine speckled (DFS-70) pattern antibodies were the most common in patients without CTD (Table 3).

\section{DISCUSSION}

Organ-specific autoimmune diseases are more frequent than systemic autoimmune diseases in patients with CSU. ${ }^{12}$ Hashimoto's thyroiditis is the main autoimmune disease associated with CSU. There is an increased incidence of antithyroid antibodies in CSU with an incidence of about $25 \% .^{13}$ It is also observed that autoantibodies such as ANA, $\mathrm{RF}$, and CTDs such as RA, SS, and SLE are reported more frequently than the normal population. ${ }^{8}$ Viswanathan et al. ${ }^{14}$ reported that ANA, anti-TPO, and anti-Tg were found in $29 \%, 26 \%$, and $6 \%$ of the patients with chronic idiopathic urticaria, respectively. The rates were also higher in female patients as 34\%, 30\%, and $8 \%$, respectively. In our study, it was found to be $24.6 \%, 18 \%$, and $26.3 \%$ in patients with CSU, while the rates were $32 \%, 20.6 \%$, and $30.7 \%$ in female patients, respectively. Although ANA positivity was similar, anti-Tg positivity was found more frequently in our study. The estimated prevalence of anti-TPO and anti-Tg positivity were reported to be between 3 and $14 \%$ in the general population. ${ }^{15,16}$ In addition, ANA was detected around $25 \%$ in the general population, with significantly higher ANA levels reported to be around $2.5 \%$ in the general population. ${ }^{17}$

In a large-population study investigating chronic urticaria and autoimmunity, it was reported that thyroid diseases were the most common accompanying diseases with CU. ${ }^{8}$ In this study, CTD was detected in approximately $2.4 \%$ of patients. These diseases were specified as RA, SS, and SLE in the order of frequency as $1.9 \%, 0.75 \%$, and $0.57 \%$ in female patients with CU. In this study, most of the patients were diagnosed with CTD after the diagnosis of $\mathrm{CU}$, particularly over a period of more than 10 years. The RF and ANA were significantly more positive often in female (2.1\% and $2.5 \%)$ and male patients $(1.2 \%$ and $0.9 \%)$ with $\mathrm{CU}$, compared to the controls. ${ }^{8}$ The number of patients with a history of CTD was fewer in our study, and most of the patients with CSU were newly diagnosed with CTD at the time of admission. The frequency of CTD in our study was quite high with $8.9 \%$ in female patients. The most common CTD was SS. In our study, SS (5.5\%), RA (1.85\%), UCTD (1.11\%), and SLE (0.37\%) were more frequently seen in female patients with CSU. In a large series study by Yong et al., ${ }^{18}$ SLE was observed with a rate of $0.2 \%$ in patients with $\mathrm{CU}$, and the incidence of other rheumatic diseases was reported to be $6.24 \%$. A recent study investigating the risk of comorbidity in patients with CU showed that RA was $1.8 \%$ and SLE was $0.3 \%$ in patients with CU. ${ }^{10}$ The rates of RA and SLE with CSU in our study were found to be similar to the literature; however, SS was found to be higher.

In the present study, the female sex was more frequent and the median age was significantly higher in the CSU patients with CTD. Also, the duration of disease was shorter in the CSU patients with CTD than without CTD. These findings suggest that CSU with CTD has later onset than CSU without CTD. As a result of the Profiling Urticaria for the Identification of Subtypes (PURIST) study, (autoimmunity was defined according to the autologous serum test, basophil histamine release assay, and basophil activation test, IgG anti- FcERI and IgG anti-IgE), and female sex was more frequent, median age was higher, CSU duration was shorter, and angioedema was more frequent in patients with autoimmune CSU; however, these differences were not statistically significant. ${ }^{19}$ In addition, total IgE levels were lower and IgG anti-TPO positivity was higher in patients with autoimmune CSU. In our study, total IgE levels were lower, and thyroid autoantibody positivity was higher in patients with CSU with CTD. Around 33 to $67 \%$ of the patients with CSU exhibit both wheals and angioedema. ${ }^{20,21}$ In our study, $41.55 \%$ of the patients had angioedema, and it was not associated with CTD.

Kawasaki disease, Henoch-Schönlein purpura, SLE, SS, and RA were found to be the most common rheumatic diseases with $\mathrm{CU}$ in a study by Chiu et al. ${ }^{22}$ SS was found more frequently 
in patients with onset of $\mathrm{CU}$ under 19 years of age, and between the ages of 40 and 59 years. There was no significant difference in a certain age range for RA; however, SLE was found more frequently in patients with onset of $\mathrm{CU}$ between the ages of 20 and 59 years. In this study, SS had a tendency to emerge after the onset of $\mathrm{CU}$, and it emerged approximately 3.45 years after the onset of $\mathrm{CU}$. The mean duration of $\mathrm{CU}$ in patients with CTD was 12 months, and the mean age was 51.5 years. In our study, the majority of CTD cases were SS, and most patients were diagnosed with CTD after the onset of CU. In other words, SS and other CTDs were diagnosed one year after the onset of CSU. Anti-DFS-70 was found to be the most common ANA subgroup autoantibodies in patients with CSU without CTD. However, the presence of other autoantibodies suggests that there is a risk of CTD development in these patients in longer follow-ups.

Sjögren syndrome is a systemic autoimmune disease that causes dryness in the eyes, mouth, larynx, pharynx, and or vagina. ${ }^{23}$ Overall prevalence of primary SS in Europe was between 0.1 and $4.8 \% .^{24,25}$ SS was seen in $4.1 \%$ of all patients in our study, and this rate was $5.5 \%$ which is higher than the literature in female patients. The female-to-male ratio of SS was 16:1 in the literature, and this ratio was $15: 1$ in our study, which is consistent with the literature. ${ }^{26-29}$ $\mathrm{SS}$, which is most common over the age of 40 years, is estimated to be the second most common autoimmune disease after Hashimoto's thyroiditis in women. ${ }^{26,30,31}$

The main limitations of the study are the lack of a control group and lack of long-term follow-up results.

In conclusion, autoimmune diseases can coexist. In our study, among the CTDs, SS is more frequent in patients with CSU. Both diseases are common in middle age and females, with certain autoantibodies. In addition, SS patients without systemic symptoms may not present to the hospital due to symptoms such as dry mouth and dry eyes. However, urticaria may be a reason for admission to the hospital, as it adversely affects the quality of life in patients with SS. Therefore, every patient diagnosed with CSU should be questioned about the symptoms of dry mouth, dry eye, and other rheumatic symptoms, particularly female patients and those later-onset CSU. SS can affect not only the exocrine glands, but also other organs. Similar to SS, other CTDs are systemic diseases that can involve many organs. Through urticaria, patients can be diagnosed at an early stage and treatment can be initiated. In addition, treatment to be applied for a CTD may be also beneficial for CSU.

Ethics Committee Approval: The approval was obtained from the Ethical Committee of Non-Invasive Clinical Research (Date/No: 18.01.2021/2021-12). The study was conducted in accordance with the principles of the Declaration of Helsinki.

Patient Consent for Publication: A written informed consent was not required from patient due to the data was obtained from the archive documents.

Data Sharing Statement: The data that support the findings of this study are available from the corresponding author upon reasonable request.

Author Contributions: Data collection, analysis, interpretation: S.Ç., G.S.; Analysis, interpretation: T.S.

Conflict of Interest: The authors declared no conflicts of interest with respect to the authorship and/or publication of this article.

Funding: The authors received no financial support for the research and/or authorship of this article.

\section{REFERENCES}

1. Zuberbier $\mathrm{T}$, Aberer W, Asero R, Abdul Latiff AH, Baker D, Ballmer-Weber $\mathrm{B}$, et al. The EAACI/ $G^{2}$ LEN/EDF/WAO guideline for the definition, classification, diagnosis and management of urticaria. Allergy 2018;73:1393-414.

2. Kolkhir P, Church MK, Weller K, Metz M, Schmetzer $\mathrm{O}$, Maurer M. Autoimmune chronic spontaneous urticaria: What we know and what we do not know. J Allergy Clin Immunol 2017;139:1772-81.

3. Altrichter S, Peter HJ, Pisarevskaja D, Metz M, Martus $\mathrm{P}$, Maurer M. IgE mediated autoallergy against thyroid peroxidase--a novel pathomechanism of chronic spontaneous urticaria? PLoS One 2011;6:e14794.

4. Hatada Y, Kashiwakura J, Hayama K, Fujisawa D, Sasaki-Sakamoto T, Terui T, et al. Significantly high levels of anti-dsDNA immunoglobulin $E$ in sera and the ability of dsDNA to induce the degranulation of basophils from chronic urticaria patients. Int Arch Allergy Immunol 2013;161 Suppl 2:154-8.

5. Schmetzer O, Lakin E, Topal FA, Preusse P, Freier $\mathrm{D}$, Church MK, et al. IL-24 is a common and specific autoantigen of IgE in patients with chronic spontaneous urticaria. J Allergy Clin Immunol 2018;142:876-82. 
6. Cugno M, Asero R, Ferrucci S, Lorini M, Carbonelli $\mathrm{V}$, Tedeschi A, et al. Elevated IgE to tissue factor and thyroglobulin are abated by omalizumab in chronic spontaneous urticaria. Allergy 2018;73:2408-11.

7. Maurer M, Eyerich K, Eyerich S, Ferrer M, Gutermuth J, Hartmann K, et al. Urticaria: Collegium Internationale Allergologicum (CIA) update 2020. Int Arch Allergy Immunol 2020;181:321-33.

8. Confino-Cohen R, Chodick G, Shalev V, Leshno M, Kimhi O, Goldberg A. Chronic urticaria and autoimmunity: Associations found in a large population study. J Allergy Clin Immunol 2012;129:1307-13.

9. Kanani A, Betschel SD, Warrington R. Urticaria and angioedema. Allergy Asthma Clin Immunol 2018;14(Suppl 2):59.

10. Ghazanfar MN, Kibsgaard L, Thomsen SF, Vestergaard C. Risk of comorbidities in patients diagnosed with chronic urticaria: A nationwide registry-study. World Allergy Organ J 2020;13:100097.

11. Kolkhir P, Metz M, Altrichter S, Maurer M. Comorbidity of chronic spontaneous urticaria and autoimmune thyroid diseases: A systematic review. Allergy 2017;72:1440-60.

12. Kolkhir P, Borzova E, Grattan C, Asero R, Pogorelov $\mathrm{D}$, Maurer M. Autoimmune comorbidity in chronic spontaneous urticaria: A systematic review. Autoimmun Rev 2017;16:1196-208.

13. Kikuchi Y, Fann T, Kaplan AP. Antithyroid antibodies in chronic urticaria and angioedema. J Allergy Clin Immunol 2003;112:218.

14. Viswanathan RK, Biagtan MJ, Mathur SK. The role of autoimmune testing in chronic idiopathic urticaria. Ann Allergy Asthma Immunol 2012;108:337-341.e1.

15. Cebeci F, Tanrikut A, Topcu E, Onsun N, Kurtulmus $\mathrm{N}$, Uras AR. Association between chronic urticaria and thyroid autoimmunity. Eur $\mathrm{J}$ Dermatol 2006;16:402-5.

16. Spencer CA, Takeuchi M, Kazarosyan M, Wang CC, Guttler RB, Singer PA, et al. Serum thyroglobulin autoantibodies: Prevalence, influence on serum thyroglobulin measurement, and prognostic significance in patients with differentiated thyroid carcinoma. J Clin Endocrinol Metab 1998;83:1121-7.

17. Wandstrat AE, Carr-Johnson F, Branch V, Gray H, Fairhurst AM, Reimold A, et al. Autoantibody profiling to identify individuals at risk for systemic lupus erythematosus. J Autoimmun 2006;27:153-60.

18. Yong SB, Su KW, Chen HH, Huang JY, Wu HJ, Wei JC. Impact of chronic urticaria on systemic lupus erythematosus: A nationwide population-based study in Taiwan. J Dermatol 2019;46:26-32.

19. Schoepke N, Asero R, Ellrich A, Ferrer M, GimenezArnau A, E H Grattan C, et al. Biomarkers and clinical characteristics of autoimmune chronic spontaneous urticaria: Results of the PURIST Study. Allergy 2019;74:2427-36.

20. Maurer M, Weller K, Bindslev-Jensen C, GiménezArnau A, Bousquet PJ, Bousquet J, et al. Unmet clinical needs in chronic spontaneous urticaria. A GA²LEN task force report. Allergy 2011;66:317-30.

21. Maurer M, Staubach P, Raap U, Richter-Huhn G, Bauer A, Ruëff F, et al. H1-antihistamine-refractory chronic spontaneous urticaria: It's worse than we thought - first results of the multicenter real-life AWARE study. Clin Exp Allergy 2017;47:684-92.

22. Chiu HY, Muo CH, Sung FC. Associations of chronic urticaria with atopic and autoimmune comorbidities: A nationwide population-based study. Int J Dermatol 2018;57:822-29.

23. Asmussen K, Andersen V, Bendixen G, Schiødt M, Oxholm P. A new model for classification of disease manifestations in primary Sjögren's syndrome: Evaluation in a retrospective long-term study. J Intern Med 1996;239:475-82.

24. Bowman SJ, Ibrahim GH, Holmes G, Hamburger $\mathrm{J}$, Ainsworth JR. Estimating the prevalence among Caucasian women of primary Sjögren's syndrome in two general practices in Birmingham, UK. Scand J Rheumatol 2004;33:39-43.

25. Drosos AA, Andonopoulos AP, Costopoulos JS, Papadimitriou CS, Moutsopoulos HM. Prevalence of primary Sjögren's syndrome in an elderly population. Br J Rheumatol 1988;27:123-7.

26. Hayter SM, Cook MC. Updated assessment of the prevalence, spectrum and case definition of autoimmune disease. Autoimmun Rev 2012;11:754-65.

27. Zandman-Goddard G, Peeva E, Shoenfeld Y. Gender and autoimmunity. Autoimmun Rev 2007;6:366-72.

28. Fairweather D, Petri MA, Coronado MJ, Cooper LT. Autoimmune heart disease: Role of sex hormones and autoantibodies in disease pathogenesis. Expert Rev Clin Immunol 2012;8:269-84.

29. Fairweather D. Autoimmune skin diseases: role of sex hormones, vitamin $\mathrm{D}$ and menopause. In: Farage MA, Miller KW, Fugate-Woods N, Maibach HI, editors. Skin, Mucosa and Menopause: Management of Clinical Issues. Berlin: Springer-Verlag; 2015. p. 359-81.

30. Nocturne G, Mariette X. Advances in understanding the pathogenesis of primary Sjögren's syndrome. Nat Rev Rheumatol 2013;9:544-56.

31. Kobayashi I, Furuta H, Tame A, Kawamura N, Kojima $\mathrm{K}$, Endoh $\mathrm{M}$, et al. Complications of childhood Sjögren syndrome. Eur J Pediatr 1996;155:890-4. 